\title{
Dispatchable Transmission in RTO Markets
}

\author{
Richard P. O’Neill, Ross Baldick, Member, IEEE, Udi Helman, Michael H. Rothkopf, and William Stewart, Jr.
}

\begin{abstract}
In this paper, we consider transmission owners that bid capacity, under appropriate Regional Transmission Organization (RTO) market rules, at a positive price into forward and spot (dispatch) auctions to derive congestion revenues. This can encompass daily, monthly, or multimonthly auctions, allowing for commitment of transmission to reflect market needs in different time periods, e.g., seasons. We provide two and three node examples and a general formulation of the auction model.
\end{abstract}

Index Terms-Dispatchable transmission, merchant transmission, standard market design.

\section{INTRODUCTION}

I $\mathrm{N}$ CURRENT electricity market designs in the United States, the owners (and, where relevant, operators) of transmission assets are essentially passive market participants. This institutional arrangement has resulted from the focus over the last decade or so on competition in generation through open access to transmission. More recently, market design proposals and policy interest in providing incentives for transmission investment and more efficient usage of the grid has suggested that some transmission owners want to be more active market participants. There is also relevant experience in this regard from the Australian electricity market.

Examples of assets owned by active market participants include, most obviously, "merchant" transmission lines that are under market-based rate regulation. ${ }^{1}$ Under appropriate circumstances, as described below, transmission owners under costbased rate regulation may also participate more actively. We assume here that each of these types of transmission-owning firms is operated within a regional spot market for wholesale electricity services under independent control by an Independent System Operator (ISO) or a Regional Transmission Organization (RTO); for the remainder of this paper, RTO will be used

Manuscript received March 22, 2003 This paper does not necessarily reflect the view of the Federal Energy Regulatory Commission. Paper no. TPWRS00566-2003

R. P. O'Neill and U. Helman are with the Federal Energy Regulatory Commission, Office of Markets, Tariffs and Rates, Washington, DC 20426 USA.

R. Baldick is with the Department of Electrical and Computer Engineering, The University of Texas, Austin, TX 78712 USA (e-mail: baldick@ece.utexas.edu).

M. H. Rothkopf is with the Department of Management Science and Information Systems, Rutgers University, Piscataway, NJ 08854 USA.

W. Stewart, Jr. is with the Graduate School of Business, College of William and Mary, Williamsburg, VA 23187 USA.

Digital Object Identifier 10.1109/TPWRS.2004.841168

${ }^{1}$ Market-based rate regulation allows a firm to sell transmission services at market prices subject to market power mitigation. generically to designate such an entity. Our proposals are intended to improve the functioning of these types of RTO markets. The conclusions reached here do not necessarily transfer to market designs in which the transmission owner also actively controls the grid. ${ }^{2}$

Bidding of transmission capacity could conceivably take different forms under different RTO market designs. However, much of the industry has converged in recent years on a particular market design, embodied by the core elements of the U.S. Federal Energy Regulatory Commission's proposed Standard Market Design (SMD) [1] and implemented heretofore in the Eastern U.S. ISO/RTO markets. ${ }^{3}$ For our purposes, the core SMD elements include locational marginal pricing (LMP), flowgate marginal pricing (FMP), and financial transmission rights (FTRs). ${ }^{4}$ In addition, the SMD proposal includes security-constrained unit commitment of supply and demand, an approach extended here to transmission.

In the context of RTOs, marginal transmission pricing and unit commitment of transmission elements would allow transmission owners to take a more active role: in principle, enabling them to bid the capacity of a transmission element, or flowgate, at a nonzero price into the RTO auction for energy, thus altering both energy prices and transmission prices. In this paper, we focus on three uses of such active bidding: to provide appropriate revenues for new projects by merchant transmission owners (see also [2]); to allow for more efficient use of existing equipment, such as phase shifting transformers; and, to encourage offers of capacity by regulated transmission owners over and above that supported currently by rate-base investment. Each of these applications builds on relevant experience in existing markets and system operations.

For example, market-based transmission pricing for merchant operators has been implemented in Australia for several

\footnotetext{
${ }^{2}$ For example, a "transco" that owns and operates the grid would be subject to a different regulatory approach, such as performance-based rates, to provide incentives to maintain and expand the grid. We do not directly compare those types of rate designs with the market-based incentives discussed here.

${ }^{3}$ These markets include PJM, the New York ISO, and ISO New England. Many elements are included in the proposed designs for the Midwest ISO, SETRANS, and the California ISO market re-design.

${ }^{4} \mathrm{An}$ LMP is typically the shadow price or Lagrange multiplier associated with delivering a marginal unit of energy at the bus or set of busses designated as the "location" (some markets, such as the New York ISO, have special pricing rules for setting LMPs at supply busses under certain conditions, e.g., allowing the most expensive unit running to set the price). LMPs can include both marginal congestion charges and marginal loss charges. Similarly, the FMP is the shadow price associated with a flowgate-a flowgate being defined generally as any transmission element or set of elements (see Section II). The FMP is equivalent to the change in the social benefit of transactions settled through the spot marke when the transmission constraint is relaxed by an increment. Finally, a financial transmission right is a property right that collects or pays marginal congestion charges but is not required for physical transmission scheduling. Section IV provides further definition of these pricing rules and property rights.
} 
years [3]..$^{5}$ In the existing RTOs, there is a nominal capacity for transmission elements and the market operates within the capabilities implied by security analysis. Emergency limits on particular elements might be invoked under some conditions, but these are largely nonmarket reliability decisions. We consider the possibility of additional capacity above nominal ratings being made available when market prices exceed costs, as an incentive to bring more such capacity reliably into service, e.g., by undertaking additional maintenance or making non-rate base investments. Nevertheless, we recognize that some of the concepts presented in this paper require technological and computational advancement, careful reliability analysis, and increased operational sophistication that will take time to implement.

In various jurisdictions, there are pre-day-ahead forward auctions for financial rights to existing transmission capacity. The forward auctions can be extended to include not just existing capacity but also bids to sell additional capacity such as may be made available by new merchant transmission construction. As shown here, in such an entry auction, a market participant can propose to build a line and the line could be dispatchable; that is, in service in some months or days and not in service during others. For example, a line used to deliver power from the Desert Southwest of the United States to California could be out of service in a good hydro year or in the winter and in service otherwise.

Market power is a problem in electricity markets that must be addressed through appropriate rules. In the static examples presented below, entry of merchant transmission capacity (approved by the RTO) and additional capacity offered by regulated firms into a spot market at any price at least maintains the status quo and can improve the total benefits (revealed surplus) of the market. These benefits may be shared unevenly amongst firms. Moreover, in the presence of barriers to entry, the owners of capacity may be able to exercise market power. Although not the focus of this paper, these issues are briefly addressed toward the end of the paper.

The paper is organized as follows. Section II gives some basic definitions. Section III offers examples on two and three node networks and involving a phase-shifting transformer. Section IV is a more technical statement of an auction with dispatchable transmission that generalizes a model in O'Neill et al. [6], [7] and is a natural extension of the SMD framework. That section presents a mathematical formulation including a proposed payment scheme. Section V discusses computational issues. Section VI briefly discusses the potential for market power in the forward and spot auction markets for energy and transmission and the need for market power mitigation. Section VII concludes.

\footnotetext{
${ }^{5}$ In Australia, the link-based offers by merchant transmission operators with controllable lines are required to be convex and do not include a "start-up" cost component. In the model we present here, a more general unit commitment formulation with an optional start-up cost is presented. Note that we do not consider generally the incentives and regulatory environment for merchant entry; for a critical review on this subject, see [4]. There is instructive experience in this regard in Australia, where the rate setting rules for regulated transmission owners gave them a market advantage over merchant transmission with market-based pricing (personal communications, Robert Outhred and Hugh Outhred, December, 2003; see also [5]).
}

\section{DEFINITIONS}

In this section, we define dispatchable transmission elements and flowgates. The basic definitions and description follow [8].

\section{A. Dispatchable Transmission Elements}

We define a dispatchable transmission element to be any transmission element, including phase angle regulators, FACTS, or DC technology, that can be operated at more than one level (even if only for short periods) and for which the bids into the market to utilize the element are not necessarily zero. With this definition, we can conceptualize transmission analogously to generation. In particular, we consider that the transmission owner bids transmission capacity into the market under rules for mitigation of market power. The RTO market rules, which include reliability rules, may allow for rejection of offered transmission if the bid costs exceed the benefits of the transmission. In some instances, this may mean disconnecting the transmission element from the grid.

Many transmission elements have emergency or short-term capacity that allows operation in excess of nominal capacity for short periods of time. Typically, operation at above the nominal capacity will increase maintenance costs or shorten the life of equipment, so that the ability to bid such short-term capacity at a nonzero price provides the owner with a mechanism to recover the costs of increased maintenance or decreased lifetime of the line. ${ }^{6}$

In some cases, the equipment may be portable and a bid to make it available at a particular location would involve relocation of the equipment. Modeling of relocation decisions may require discrete decision variables. More generally, bids to build or put in service transmission lines or bids to offer to change the settings of phase-shifting transformers require discrete decision variables in the auction formulation. For example, the New York ISO may reset the phase-shifting transformers several times per day, but they have "start-up" and "shut-down" costs.

\section{B. Flowgates}

The North American Electric Reliability Council (NERC) defines flowgates as the locations or set of locations in the electricity network that are specifically monitored for reliability (security) purposes. Following [8, Section II-A], we adopt a more general definition of flowgate for use in the markets envisioned in the SMD proposal: identifying all transmission elements (lines, transformers, etc.), or sets of such elements, as "flowgates." The NERC defined flowgates are thus a subset of our set. The more general definition that we use allows transmission elements to be dispatched with reservation bids in the auction.

As discussed in [8], in this formulation, each transmission element has two "elemental" flowgates: one in each direction. Each elemental flowgate has capacity, in MW, in a single (prespecified) direction. This construct allows all elemental flowgate capacity prices to be nonnegative, but is not necessarily the best computational formulation. In the examples that follow, we

\footnotetext{
${ }^{6}$ Reference [9] describes one approach to assessing the cost of overloading a line in terms of the decrease in lifetime of the line.
} 
TABLE I

Generation And Transmission BIDS FOR Two Node NeTwork SHOwn IN Fig. 1

\begin{tabular}{l||r|r|r|r}
\hline \hline Market participant & Generator 1 at A & Generator 2 at A & Transmission from A to B & Generator at B \\
\hline Bid price (\$/MWh) & 10 & 20 & 10 & 40 \\
\hline Maximum quantity (MW) & 90 & 100 & See Table II & 160 \\
\hline \hline
\end{tabular}

TABLE II

Market Clearing Prices and Revealed Surplus for Three Demand Levels and With and Without Incremental Transmission FOR Two NODE NETWORK SHOWN IN FIG. 1

\begin{tabular}{l||r|r||r|r||r|r}
\hline \hline Demand at B (MW) & \multicolumn{2}{|c||}{80} & \multicolumn{2}{|c||}{105} & \multicolumn{2}{|c}{200} \\
\hline \hline Incremental transmission from A to B (MW) & 0 & 10 & 0 & 10 & 0 & 10 \\
\hline Revealed surplus (\$/h) & 3200 & 3200 & 3950 & 4000 & 4900 & 5000 \\
\hline LMP at A (\$/MWh) & 10 & 10 & 20 & 20 & 20 & 20 \\
\hline LMP at B (\$/MWh) & 10 & 10 & 40 & 30 & 40 & 40 \\
\hline FMP for AB (\$/MWh) & 0 & 0 & 20 & 10 & 20 & 20 \\
\hline \hline
\end{tabular}

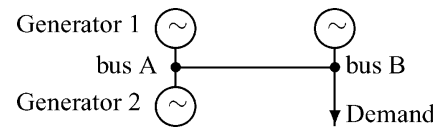

Fig. 1. Two node network.

designate the direction of flow on an elemental flowgate by the order of the nodes in the labeling. For example, if A and B are adjacent nodes in the network then "AB" is the elemental flowgate for flow from $\mathrm{A}$ to $\mathrm{B}$ and $\mathrm{BA}$ is the elemental flowgate for flow from B to A.

\section{Auction EXAmples ON Two AND THREE NODE NETWORKS}

To show how to include dispatchable transmission in the organized market, we set up and conduct sample auctions on two and three node networks. The two node network serves to illustrate the basic concept, while the three node network demonstrates it in the context of loop flow. For purposes of exposition, we assume that in addition to base-case transmission capability there is a way to increase the capacity, possibly involving new construction, relocation of equipment, or with additional maintenance or operations costs. This incremental transmission capacity is bid into the auction at a nonzero price and the auction is cleared using the transmission bids as well as the generation and demand bids.

For simplicity in the model, we neglect losses. These can be incorporated. Moreover, the auction model can accommodate multiple time periods, but we do not explicitly represent them here. The auction model could be used for planning, reliability, forward markets, or dispatch markets and can represent single or, with minor extensions, multiple time periods.

\section{A. Two Node Network Auctions}

Consider the two node network shown in Fig. 1, which shows two busses, $\mathrm{A}$ and $\mathrm{B}$. There are two generators at bus A, one generator at bus B, and demand at bus $\mathrm{B}$. There is $100 \mathrm{MW}$ of base-case transmission capability between A and B; however, we assume that there is also a way to increase the capability between A and B by $10 \mathrm{MW}$. We model two ways in which this might occur:
1) through increasing the allowable flows on existing lines, perhaps incurring additional maintenance costs in the long-run;

2) through additional transmission capacity being put in service between $A$ and $B$.

The difference between the two alternatives is that in the second case we must model the sharing of flow between the existing and additional transmission lines and explicitly model the decision to put the line in service. In the first alternative, the additional capacity involves no change in the network topology or impedance. We consider these alternatives in the following sections.

1) Additional Capacity With No Change in Network Topology: In this section, we present and analyze auctions for the generation and transmission bids in Table I. Three different levels of demand are considered as shown in Table II and for each of these we consider the case where no incremental transmission from $\mathrm{A}$ to $\mathrm{B}$ is made available and the case where $10 \mathrm{MW}$ of incremental transmission from $\mathrm{A}$ to $\mathrm{B}$ is made available. This incremental transmission is made available without change in the network and the bid price of $\$ 10 / \mathrm{MWh}$ is assumed to be payable on each MW of flow above $100 \mathrm{MW}$ from A to B. For all cases, the demand bid price is $\$ 50 / \mathrm{MWh}$.

We consider auctions for each of the three demand levels and with and without incremental transmission, assuming the generation and transmission bids from Table I. Revealed surplus (defined as the difference between bid value of consumption and bid costs of production for accepted bids and denominated on a per hour basis), LMPs, and FMPs resulting from the auctions for each of the three demand levels are shown in Table II. The quantities, revenues (negative numbers associated with demands are payments), and rents (defined for generators as the revenues in excess of the bid costs and defined for demand as the bid willingness to pay in excess of payments) are presented in Table III for the cases from Table II where extra transmission from A to B was bid.

From Tables II and III with demand at $80 \mathrm{MW}$, the extra transmission capacity is not needed and not dispatched and no payment is made for the incremental transmission.

When demand is $105 \mathrm{MW}$, five units of the dispatchable transmission capacity are selected. The extra capacity is economic 
TABLE III

QuANTITIES, REVENUES, AND SCARCITY RENTS AT THREE DEMAND LEVELS With 10 MW OF INCREMENTAL TRANSMISSION MADE AVAILABLE FOR Two NODE NeTwORK SHOWN IN FIG. 1

\begin{tabular}{|c|c|c|c|c|c|c|c|c|c|}
\hline Demand at B (MW) & \multicolumn{3}{|c|}{80} & \multicolumn{3}{|c|}{105} & \multicolumn{3}{|c|}{200} \\
\hline Market participant & $\begin{array}{r}\text { quantity } \\
\text { (MW) }\end{array}$ & $\begin{array}{r}\text { revenue } \\
(\$ / h)\end{array}$ & $\begin{array}{l}\text { rent } \\
(\$ / h)\end{array}$ & $\begin{array}{r}\text { quantity } \\
\text { (MW) }\end{array}$ & $\begin{array}{r}\text { revenue } \\
(\$ / \mathrm{h})\end{array}$ & $\begin{array}{l}\text { rent } \\
(\$ / h)\end{array}$ & $\begin{array}{r}\text { quantity } \\
\text { (MW) }\end{array}$ & $\begin{array}{r}\text { revenue } \\
(\$ / h)\end{array}$ & $\begin{array}{r}\text { rent } \\
(\$ / h)\end{array}$ \\
\hline Generator 1 at $\mathrm{A}$ & 80 & 800 & 0 & 90 & 1800 & 900 & 90 & 1800 & 900 \\
\hline Generator 2 at $\mathrm{A}$ & 0 & 0 & 0 & 15 & 300 & 0 & 20 & 400 & 0 \\
\hline Generator at B & 0 & 0 & 0 & 0 & 0 & 0 & 90 & 3600 & 0 \\
\hline Base-case transmission $\mathrm{A}$ to $\mathrm{B}$ & 80 & 0 & 0 & 100 & 1000 & 1000 & 100 & 2000 & 2000 \\
\hline Incremental transmission $\mathrm{A}$ to $\mathrm{B}$ & 0 & 0 & 0 & 5 & 50 & 0 & 10 & 200 & 100 \\
\hline Demand at B & 80 & -800 & 3200 & 105 & -3150 & 2100 & 200 & -8000 & 2000 \\
\hline
\end{tabular}

and lowers the LMP at B from \$40/MWh to $\$ 30 / \mathrm{MWh}$ and the FMP on $\mathrm{AB}$ from $\$ 20 / \mathrm{MWh}$ to $\$ 10 / \mathrm{MWh}$. Incremental transmission decreases the congestion rental for the base-case transmission. The revealed surplus (the objective function value) increases by $\$ 50 / \mathrm{h}$; however, a significant fraction of the rent has been shifted from the demand to Generator 1 at A. ${ }^{7}$ When demand is $200 \mathrm{MW}$, all the available units of transmission are dispatched. Incremental transmission does not change the congestion rental for the base-case transmission. The LMPs and FMPs are the same as when demand is 105 MW without the incremental transmission bids.

Notice that whenever transmission bids capacity over and above the base case capacity, the revealed surplus is always greater than or equal to the revealed surplus without transmission bidding. That is, allowing bidding of capacity above base case capacity never leads to a reduction in net benefits. This statement will be qualified in the context of market power in Section VI.

2) Additional Capacity Due to a Change in the Network: In this section, we imagine that the increase in capacity is due to the construction of a new line in the corridor from A to B. For concreteness, we will assume that the admittance of the new line is one-tenth of the admittance of the existing line between $A$ and $\mathrm{B}$, so that power flows in the ratio of 10:1 between the existing and new line when the new line is in service. In this case, the bid price for flow along the line is assumed to be payable for the flow that results from the sharing of flow between the new and existing line between A and B. Moreover, in addition to bidding a price per MWh for flow along the new line, we assume that the owner of the new line has a reservation price of $\$ 75 / \mathrm{h}$. (In forward markets, the time period may be multiple years and "costs" could include construction costs.)

The cost structure of a reserve price together with a price for flow is analogous to a no-load charge plus energy charge for a thermal generator, making the total bid cost function nonconvex. Such nonconvexities pose problems for energy markets. In unit commitment markets such as in PJM and the New York ISO, payments for start-up and no-load costs (in addition to the energy commodity payment) can be made to cover the seller's bid. We will propose an analogous approach in Section IV for setting prices.

Besides the changes to accommodate the reservation price, all other bid and quantity parameters for the auction are as in

\footnotetext{
${ }^{7}$ Increases could be hedged in forward markets, making the important measure the revealed surplus. With truthful bidding, revealed surplus is the true market surplus.
}

Table I. We again assume demand levels of $80 \mathrm{MW}, 105 \mathrm{MW}$, and $200 \mathrm{MW}$.

Unlike the previous case, in this auction there is a discrete variable representing the choice to put the $10 \mathrm{MW}$ in service or not. Putting the line in service incurs the $\$ 75 / \mathrm{h}$ reservation price and, in addition, payment for the flow along the line. Unlike in the previous auction, we must explicitly consider the flow along the line due to the admittance of the line and consider the reservation price. In general, this considerably complicates the formulation of the auction because of the discrete variables. In this particular case, however, we can analyze the results by making use of the calculations from the previous case.

For the $80 \mathrm{MW}$ demand level, the results from Table II show the incremental transmission is uneconomic since all demand can be supplied from the cheaper generation resource using the existing line. That is, there is no benefit in putting the additional line in service, while putting it in service would incur both the reservation price and the payment for flow. The auction solution corresponds to the zero transmission case for the $80 \mathrm{MW}$ demand level in Table II.

For the 105 MW demand level, the incremental transmission allows for additional imports of cheaper energy. In particular, optimal dispatch given that the line is in service and given the transmission flow price would involve importing $105 \mathrm{MW}$. Of these imports, the ratios of admittances imply that approximately 95.5 MW would flow on the existing line and 9.5 MW would flow on the additional capacity. For this demand level, the combination of the reservation price and the sharing of flow between the two lines means that the payment to the line owner, if the line were in service, would exceed its benefits, with revealed surplus of $\$ 3925 / \mathrm{h}$. This value is less than the revealed surplus of $\$ 3950 / \mathrm{h}$ with the line out of service. In summary, the auction solution leaves the line out of service, corresponding to the zero transmission case for the $105 \mathrm{MW}$ demand level in Table II. The reservation price would have to be less than $\$ 50 / \mathrm{h}$ in order for it to be put in service, given the $\$ 10 / \mathrm{MWh}$ price for flow of power.

For the 200 MW demand level, the incremental transmission again allows for additional imports of cheaper energy. Optimal dispatch given that the line is in service and given the transmission flow price would involve importing $110 \mathrm{MW}$. The auction solution brings the line in service, corresponding to the $10 \mathrm{MW}$ transmission case for the $200 \mathrm{MW}$ demand level in Table II. The only difference between the auction result and that shown in Table II is that the revealed surplus is $\$ 4925 / \mathrm{h}$ instead of $\$ 5000 / \mathrm{h}$ because of the reservation price incurred for having the line in service. 
TABLE IV

GENERATION AND TRANSMISSION BIDS FOR THREE NODE NETWORK SHOWN IN FIG. 2

\begin{tabular}{l||r|r|r|r|r}
\hline \hline \multicolumn{1}{l||}{} & \multicolumn{4}{c|}{ Generator } & Transmission \\
Market participant & 1 at A & 2 at A & at B & at C & from A to B \\
\hline Bid price (\$/MWh) & 10 & 20 & 30 & 25 & 10 \\
\hline Maximum quantity (MW) & 110 & 300 & 300 & 300 & See Tables V and VI \\
\hline \hline
\end{tabular}

TABLE V

Market Clearing Prices and Revealed Surplus at Two Demand LeVels and With and Without Incremental Transmission for THREE NODE NETWORK SHOWN IN FIG. 2

\begin{tabular}{|c|c|c|c|c|c|}
\hline Demand at B (MW) & \multicolumn{3}{|c|}{200} & \multicolumn{2}{|c|}{300} \\
\hline Incremental transmission from A to B (MW) & 0 & 10 & 80 & 0 & 80 \\
\hline Revealed surplus $(\$ / h)$ & 6600 & 6650 & 6767 & 8600 & 9000 \\
\hline LMP at $\mathrm{A}(\$ / \mathrm{MWh})$ & 20 & 20 & 20 & 20 & 20 \\
\hline Total generation at $\mathrm{A}(\mathrm{MW})$ & 110 & 130 & 200 & 110 & 260 \\
\hline LMP at B (\$/MWh) & 30 & 30 & 26.67 & 30 & 30 \\
\hline Total generation at B (MW) & 10 & 0 & 0 & 110 & 20 \\
\hline LMP at $\mathrm{C}(\$ / \mathrm{MWh})$ & 25 & 25 & 23.33 & 25 & 25 \\
\hline Total generation at $\mathrm{C}(\mathrm{MW})$ & 80 & 70 & 0 & 80 & 20 \\
\hline FMP for $\mathrm{AB}(\$ / M W h)$ & 15 & 15 & 10 & 15 & 15 \\
\hline
\end{tabular}

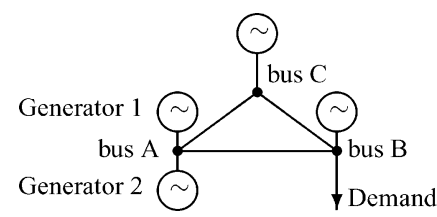

Fig. 2. Three node network.

\section{B. Three Node Network Auctions}

Now consider the three node network shown in Fig. 2, which shows three busses, A, B, and C. There are two generators at bus $\mathrm{A}$, one generator at bus $\mathrm{B}$, demand at bus $\mathrm{B}$, and one generator at bus $\mathrm{C}$. There are three transmission lines, $\mathrm{AB}, \mathrm{AC}$, and $\mathrm{CB}$.

Each of the three transmission lines has base case capacity of $100 \mathrm{MW}$ and they all have the same admittance. We consider loop flow for this system but ignore contingency constraints in this example when calculating the capability to deliver power to demand at B. (Alternatively, we can interpret Fig. 2 as showing the conditions under the most binding contingency for the system.)

We again consider that there is a way to increase the ability to import cheaper energy to $\mathrm{B}$. We again model two ways in which this might occur:

1) through increasing the allowable flows on existing lines;

2) through adjustment of the settings of a phase-shifting transformer installed on line $\mathrm{AB}$, enabling better utilization of the transmission capability.

The difference between the two alternatives is that in the second case we must model the change in the share of flow between the lines in the network. In the first alternative, the additional capacity on $\mathrm{AB}$ does not change the sharing of flows between lines in the network. We consider these alternatives in the following sections.

1) Additional Capability With No Change in Network: In this section, we consider two cases: where the capacity between $\mathrm{A}$ and $\mathrm{B}$ can be increased by $10 \mathrm{MW}$ and where the capacity can be increased by $80 \mathrm{MW}$. In both cases, we assume that the additional capacity does not involve a change in the admittance of the line.

The generation bids are as presented in Table IV. For all cases, the transmission bid price is $\$ 10 / \mathrm{MWh}$ and the demand bid price is $\$ 50 / \mathrm{MWh}$. We consider two levels of demand at $\mathrm{B}$, namely $200 \mathrm{MW}$ and $300 \mathrm{MW}$.

Various combinations of the two levels of incremental transmission capacity and the two different levels of demand are considered as shown in Table V. We also show the case for no incremental transmission capacity. We consider auctions for each of the two demand levels, assuming the generation and transmission bids from Table IV. Various LMPs and FMPs resulting from the auction for each of the three demand levels are shown in Table V. The quantities, revenues, and rents are presented in Table VI for the cases from Table V where extra transmission from A to B was bid.

From Table V with demand at $200 \mathrm{MW}$ and with incremental transmission capacity from A to B of $10 \mathrm{MW}$, the LMPs and FMPs are the same with and without dispatchable transmission capacity. However, the incremental transmission capability is still valuable since the surplus increases by $\$ 50 / \mathrm{h}$ with dispatchable transmission capacity compared to without.

With demand at $200 \mathrm{MW}$ and incremental transmission capacity from A to B of $80 \mathrm{MW}, 33.3 \mathrm{MW}$ units of the extra capacity are economic and lowers the LMP at B from $\$ 30 / \mathrm{MWh}$ to $\$ 26.67 / \mathrm{MWh}$, lowers the LMP at $\mathrm{C}$ from $\$ 25 / \mathrm{MWh}$ to $\$ 23.33 / \mathrm{MWh}$, and lowers the FMP on $\mathrm{AB}$ from $\$ 15 / \mathrm{MWh}$ to $\$ 10 / \mathrm{MWh}$. When demand is $300 \mathrm{MW}$, all the available units of transmission are dispatched, the LMPs and FMPs are the same as without incremental transmission, but the revealed surplus (the objective function value) increases by $\$ 400 / \mathrm{h}$ compared to the case where no additional capacity is available.

2) Additional Capability Through Operation of a Phase-Shifting Transformer: In this section, instead of considering additional transmission capacity from A to B, we consider the availability of a phase-shifting transformer that can shift flow from $\mathrm{AB}$ to the lines $\mathrm{AC}$ and $\mathrm{CB}$. Adjusting the 
TABLE VI

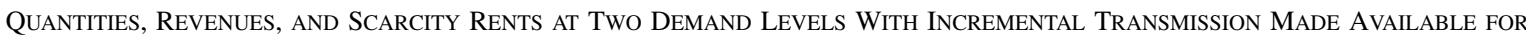
THREE NODE NETwORK SHOWN IN FIG. 2

\begin{tabular}{|c|c|c|c|c|c|c|c|c|c|}
\hline Demand at B (MW) & \multicolumn{3}{|c|}{200} & \multicolumn{3}{|c|}{200} & \multicolumn{3}{|c|}{300} \\
\hline $\begin{array}{l}\text { Incremental transmission } \\
\text { from A to B (MW) }\end{array}$ & \multicolumn{3}{|c|}{10} & \multicolumn{3}{|c|}{80} & \multicolumn{3}{|c|}{80} \\
\hline Market participant & $\begin{array}{r}\text { quantity } \\
\text { (MW) }\end{array}$ & $\begin{array}{r}\text { revenue } \\
(\$ / \mathrm{h})\end{array}$ & $\begin{array}{r}\text { rent } \\
(\$ / h)\end{array}$ & $\begin{array}{r}\text { quantity } \\
\text { (MW) }\end{array}$ & $\begin{array}{r}\text { revenue } \\
(\$ / h)\end{array}$ & $\begin{array}{r}\text { rent } \\
(\$ / h)\end{array}$ & $\begin{array}{r}\text { quantity } \\
\text { (MW) }\end{array}$ & $\begin{array}{r}\text { revenue } \\
(\$ / h)\end{array}$ & $\begin{array}{r}\text { rent } \\
(\$ / h) \\
\end{array}$ \\
\hline Generator 1 at $\mathrm{A}$ & 110 & 2200 & 1100 & 110 & 2200 & 1100 & 110 & 2200 & 1100 \\
\hline Generator 2 at $\mathrm{A}$ & 20 & 400 & 0 & 90 & 1800 & 0 & 150 & 3000 & 0 \\
\hline Generator at B & 0 & 0 & 0 & 0 & 0 & 0 & 20 & 600 & 0 \\
\hline Generator at $\mathrm{C}$ & 70 & 1750 & 0 & 0 & 0 & 0 & 20 & 500 & 0 \\
\hline Base-case transmission $\mathrm{A}$ to $\mathrm{B}$ & 100 & 1500 & 1500 & 100 & 1000 & 1000 & 100 & 1500 & 1500 \\
\hline Incremental transmission $\mathrm{A}$ to $\mathrm{B}$ & 10 & 150 & 50 & 33.3 & 333 & 0 & 80 & 1200 & 400 \\
\hline Demand at B & 200 & -6000 & 4000 & 200 & -5333 & 4667 & 300 & -9000 & 6000 \\
\hline
\end{tabular}

sharing of flow between lines in the network allows for better utilization of transmission capacities [10].

If we assume similar bids to those in the previous section, with offered shifts of flow by the phase-shifting transformer of up to $10 \mathrm{MW}$ and $80 \mathrm{MW}$, respectively, at a price of $\$ 10 / \mathrm{MWh}$ then, using the results of Table V, we find that essentially the same outcomes occur, with the phase-shifting transformer being dispatched to shift various amounts of flow from $\mathrm{AB} .{ }^{8}$

In more complicated networks, phase-shifting transformers will result in different clearing prices and different transmission line flows compared to the case with incremental transmission capability of the same capacity. However, the presence of either incremental transmission capability or phase-shifting transformers cannot decrease the revealed surplus.

3) Phase-Shifting Transformer With Reservation Price for Changing Shift: In the previous section, the phase-shifting transformer bid consisted only of a price for power shifted. However, electromechanical phase-shifting transformers suffer from wear-and-tear each time their setting is changed. An owner may wish to bid in a price for changing the setting in addition to the price for flow shifted.

Representation of a price for changing the setting is analogous to a price for starting up a thermal generator in that it requires a discrete decision variable to represent it and, moreover, decisions about the exercise of such changes requires consideration over a time horizon. In particular, it may or may not be optimal to change the setting of a phase-shifting transformer, depending on the time that will elapse until the setting must be changed again, just as it may or may not be optimal to shut-down or start-up a generator, depending on the time until the state of the generator must be changed again.

To analyze this case, we consider a day-ahead dispatch and suppose that demand at B is $200 \mathrm{MW}$ throughout the 24 hours of the day. Moreover, we assume that the initial state of the phaseshifting transformer is that it is providing no shift in power flow. In addition to the bid for shifting flow of $\$ 10 / \mathrm{MWh}$ with a capability of up to $10 \mathrm{MW}$, we now assume that there is a charge of $\$ 500$ for each change in the setting of the transformer.

Given no change in the phase-shifter setting then, using the results of Table $\mathrm{V}$, the revealed surplus over the 24 hours would

\footnotetext{
${ }^{8}$ Phase-shifting transformers actually control the angle change across their terminals; however, under the DC approximation, this can be represented as a shift in flow.
}

be $\$ 158400$. If the phase-shifter setting is adjusted to shift 10 MW from $\mathrm{AB}$ then the revealed surplus over the 24 hours would be $\$ 159$ 100. Neglecting consideration of any subsequent need to change the phase-shifter setting again, the optimal outcome would therefore be to change the setting of the phase-shifter. However, if the charge to change the setting of the phase-shifter were to increase by more than $\$ 700$ to be more than $\$ 1200$ then the revealed surplus over the 24 hours would be insufficient to justify changing the setting.

\section{Dispatchable Transmission IN THE General AUCTION MODEL}

In this section, we show how the dispatchable transmission bids can be accommodated in an auction for energy and transmission rights. This auction formulation is a generalization of O'Neill et al. [6], [7], which in turn extended the auction models (and notation) in Harvey et al. [11] and Chao and Peck [12] (for further discussion, see also Chao et al. [13], Hogan [14], [15], and Ruff [16]). Those interested in a fuller account of the issues in transmission rights specification, auction design, revenue adequacy and solution procedures should refer to these papers. ${ }^{9}$

The auction design presents a payment scheme that is analogous to that used for unit commitment markets in current ISOs/RTOs and included in the SMD proposal.

\section{A. The Nonlinear Case}

The following simplified general model of the auction is based on the form proposed in O'Neill et al. [6]. We first present a version of the auction model with nonlinear transmission constraints and a nonlinear bid function for energy. This is a nodal model, but we do not explicitly show the indexing of nodes and transmission network elements. The model is

$$
\begin{aligned}
\max _{t, g, z} B(g)-b(t)-c(z), & \\
\text { such that } A g-y & =0, \quad(\pi) \\
K(y, z, t) \leq f, \quad(\mu) &
\end{aligned}
$$

${ }^{9}$ In particular, the sequence of forward and spot auctions with dispatchable transmission can be shown to be revenue adequate; that is, the market operator collects sufficient revenue to pay the holders of transmission rights. The key assumption here is that transmission bidding that brings additional transfer capability into the market (with market power under control) always increases the auction economic surplus. A mathematical proof is a straightforward extension of the proof found in [6]. 


$$
\begin{aligned}
& 0 \leq z t_{\ell} \leq t \leq z t_{u}, \quad\left(\rho_{\ell}, \rho_{u}\right) \\
& 0 \leq g_{\ell} \leq g \leq g_{u}, \quad\left(\psi_{\ell}, \psi_{u}\right) \\
& z_{i} \in\{0,1\} .
\end{aligned}
$$

Unless otherwise stated, each variable or parameter in lower case is a vector, each function is in upper case, and each matrix of parameters is in upper case. The objective of the auction is to maximize the revealed surplus of the bids for generation, demand, and incremental transmission (based on values expressed by the bidders). The term $B(g)$ in the objective represents the benefits of consumption minus the costs of generation and is a function of the net generation $g$ of each generator or demand.

The term $b(t)$ represents the offers by transmission owners for providing transmission capability or shifting of generation by a phase-shifting transformer, with entries in $b$ corresponding to bid prices (in $\$ / \mathrm{MWh}$ ) and entries in $t$ corresponding to the amount of incremental transmission utilized. The term $c(z)$ represents the costs of transmission capacity reservation prices, with entries in $c$ corresponding to reservation prices (in $\$ / \mathrm{h}$ ) and entries in $z$ representing discrete decisions for incremental transmission.

For simplicity, we have assumed that discrete decisions can be represented as zero-one variables and that these specify whether or not the incremental transmission is in service through the constraints (3). However, generalizations to include, for example, charges for changing state for phase-shifting transformers that are analogous to start-up and shut-down costs for generators are straightforward conceptually, if not computationally. They also require extension to a multiperiod model.

The Lagrange multiplier associated with each constraint is shown in parenthesis. The objective of the auction is to maximize the revealed surplus from the auction bids. Other bid parameters are in the set of auction constraints (1)-(4). The parameters associated with bids for generation and demand $g$, include $A$, the net injections at each node for each bid, and $g_{l}$, and $g_{u}$, the lower and upper bounds (quantities) on the bids. For simplicity, we omit integer variables for generators.

The constraint equations (1) are the energy balance constraint (for each node). This equation translates the net injections by participants into net injections at each node. The entries in $A$ are $0, \pm 1$. The constraint equations (2) are the set of constraints associated with transmission network constraints, such as Kirchhoff's Laws, and transfer capacities. The transmission function $K$ translates net injections, $y$, into flows, $K(y, z, t)$, on transmission elements in the topology specified by the in-service incremental transmission corresponding to entries in $z$ that are equal to one. We let the flow in each direction on a line be a separate constraint. The vector of constraints on transmission elements that make up the base case network such as thermal, reactive power and stability constraints are represented by the vector $f$. The limits on the incremental capacity are specified by the limits $t_{\ell}$ and $t_{u}$.

The Lagrange multipliers on the auction constraints are $\pi, \mu$, $\rho_{\ell}, \rho_{u}, \psi_{\ell}, \psi_{u}$. The dual variable vector, $\pi$, are the shadow prices for energy (at each node). That is, $\pi$ contains the LMPs. The dual variable vector, $\mu$, are the shadow prices on transmission network constraints. That is, $\mu$ contains the FMPs.
The nonlinear model can be used to extend existing forward auctions for transmission rights solved on an AC load flow model (as in the New York ISO), or as a basis for new transmission auctions.

\section{B. The Linear Case and Auction Properties}

For computational purposes, energy and transmission auctions are often approximated and solved as linear models (for example, the transmission rights auctions in PJM). To convert the nonlinear model above to a linear model, we require a linear bid function, linearization of the transmission constraints using the DC load flow approximation (with the resulting matrix $D(z)$ of power transfer distribution factors (PTDFs) and matrix $E(z)$ relating flows on incremental capacity to flows on the base case transmission, both depending on $z$ ), and a constraint for flow in each direction. Moreover, the bid function $B$ is redefined to be a row vector of bid prices for $g$. (See also [7]).

Linearization facilitates conversion of the auction solution into a payment scheme. The resulting linearized auction model is

$$
\begin{aligned}
& \max _{t, g, z} B g-b t-c z, \\
& \text { such that } A g-y=0, \quad(\pi) \\
& D(z) y-E(z) t \leq f, \quad(\mu) \\
& 0 \leq z t_{\ell} \leq t \leq z t_{u}, \quad\left(\rho_{\ell}, \rho_{u}\right) \\
& 0 \leq g_{\ell} \leq g \leq g_{u}, \quad\left(\psi_{\ell}, \psi_{u}\right) \\
& z_{i} \in\{0,1\} \text {. }
\end{aligned}
$$

Once this auction problem is solved for a solution $t^{\star}, g^{\star}, z^{\star}$, the optimal levels of the network topology $z^{\star}$ are known. Define $D^{\star}=D\left(z^{\star}\right)$ and $E^{\star}=E\left(z^{\star}\right)$. Substituting for the transmission function yields the linear program:

$$
\begin{aligned}
& \max _{t, g, z} B g-b t-c z^{\star}, \\
& \text { such that } A g-y=0, \quad(\pi) \\
& D^{\star} y-E^{\star} t \leq f, \quad(\mu) \\
& 0 \leq z t_{\ell} \leq t \leq z t_{u}, \quad\left(\rho_{\ell}, \rho_{u}\right) \\
& 0 \leq g_{\ell} \leq g \leq g_{u}, \quad\left(\psi_{\ell}, \psi_{u}\right) \\
& z=z^{\star} \quad(\eta),
\end{aligned}
$$

where we have added a constraint for each discrete value fixed at its optimal value and have added Lagrange multipliers $\eta$ for these constraints (see [17]).

By complementary slackness, $\left(-\pi+\mu D^{\star}\right) y=0$. If $y \neq 0$ then $\pi=\mu D^{\star}$. That is, the LMPs, $\pi$ and the FMPs, $\mu$, are related by a linear transformation using the PTDFs.

A payment scheme for a dispatchable transmission element that is closely related to the settlement scheme for unit commitment in the eastern U.S. RTO markets is to pay the FMPs, if these cover the reservation price and bid price for the element. If the FMPs are insufficient, then an extra side-payment is made to cover the reservation prices.

\section{Computational IsSues}

Using current hardware and software, a dispatchable transmission auction could require significant solution time. How- 
ever, advances in technology have dramatically increased solution speed for problems of this type over the past decade. ${ }^{10}$ Further computational improvements are necessary before dispatchable transmission auctions that require quick solutions, such as the day-ahead auction markets, can be implemented. Auctions for longer-term transmission rights held, e.g., weekly, monthly or seasonally, can be given additional time if necessary to solve and therefore could be a nearer term target for implementation. Such auctions could be conducted iteratively, using relaxed (e.g., Lagrangian) solutions in each iteration. Finally, the auction allowing biddable transmission but without discrete variables would clearly be much easier to solve with current software.

\section{MARKet POWER Mitigation}

The addition of biddable incremental transmission represents a departure from existing energy market rules. When market rules change, the incentives change and we should expect that gaming strategies for dispatchable transmission would appear and that market power mitigation rules to counter these strategies may be necessary. In general, as in the energy markets, the focus of mitigation should be on the day-ahead and real-time (spot) markets, where withholding of transmission (physical or economic) that is deemed inappropriate can be detected and prevented. (For further discussion of withholding by merchant entrants, see also [19]). Transmission bidding in the longerterm auction markets for transmission rights probably should not raise market power concerns unless the transmission owner can create barriers to entry. However, the intricacies of market power in the transmission markets merits consideration beyond that attempted here.

A gaming issue that results from our proposal to allow a transmission owner to bid beyond nominal capacity is that there is then a greater incentive to understate the nominal capacity of its transmission in order to capture more payment from incremental transmission. If the RTO is technically competent to make the nominal capacity judgement, the ability to deceive is lowered. As always, the RTO is responsible for reliability and can override market outcomes. Hopefully, as proper economic incentives are introduced, the need to intervene for reliability will be reduced.

The appearance of dispatchable transmission that is independent of other market participants can reduce the market power of the generators by allowing additional transmission coupled with distant generation to compete partially with local generation. Since opportunities for incremental capacity on existing lines may involve increased maintenance costs, such incremental capacity is likely to be sustainable or profitable only for short periods at a time. However, since opportunities for exercise of generator market power are also typically short-lived, occurring

\footnotetext{
${ }^{10}$ For example, over the latter years of the 1990 s, advances in new software (holding hardware constant) for mixed integer programming used for an optimal solution to the generation unit commitment problem improved solution time by a factor of at least 64 (see discussion in [18, ch. 1]). In recent testing of mixed integer programming versus Lagrangian relaxation to solve the day-ahead auction market in PJM, the mixed integer programming algorithm out-performed the current Lagrangian relaxation approach in both time and accuracy (private communication with Andy Ott).
}

when supply is tight, the opportunity to offer incremental transmission capability at judicious times may have a significant effect on the exercise of generator market power.

\section{SUMMARY AND CONCLUDING OBSERVATIONS}

The biddable/dispatchable transmission rights introduced here can provide the market with greater efficiency and competition. They can be included in RTO markets implementing energy and transmission auctions that calculate forward and spot prices on specific transmission elements and hence provide a mechanism for incentives to increase transmission capability. Market power monitoring and mitigation would need to be developed to ensure that the social benefits are captured.

Finally, this paper would be remiss without acknowledging possible fairness issues associated with transmission auctions, although these are beyond the scope of the paper. The entry and dispatch of possibly large transmission assets will create winners and losers among buyers and sellers of electricity products. The existence of losers (and the continued existence of contracts and expectations based on the prior regulatory compact) raises political issues related to fairness, compensation, and the ability of uncompensated losers to block the addition of worthwhile transmission or efficient transmission dispatch decisions. Moreover, since transmission sector regulation will continue to evolve, careful policy decisions will be needed to avoid potentially adverse implications for investment in both generation and transmission.

\section{ACKNOWLEDGMENT}

The authors would like to thank C. Lausten, P. McCoy, A. Ott, H. Outhred, R. Outhred, and J. Rossignoli for helpful comments. Particular thanks to H. Outhred and R. Outhred for the detailed explanations of the merchant transmission pricing rules and the subsequent market experience in Australia.

\section{REFERENCES}

[1] United States of America Federal Energy Regulatory Commission, "Standard Market Design and Structure Notice of Proposed Rulemaking," 18 CFR Part 35, Docket Number RM01-12-000, Sep. 2002.

[2] S. Dekrajangpetch and G. B. Sheble, "Application of auction results to power system expansion," in Int. Conf. Electric Utility Deregulation and Restructuring and Power Technologies 2000, London, U.K., Apr. 2000, pp. $142-146$.

[3] (1998, Nov.) National Electricity Code Administrator (Australia)"Entrepreneurial Interconnectors: Safe Harbour Provisions," Report of working group on inter-regional hedges and entrepreneurial interconnectors. [Online] Available www.neca.com.au

[4] P. Joskow and J. Tirole, Merchant Transmission Investment, Dept. Economics, Mass. Inst. Technol., Cambridge, Feb. 2003.

[5] S. Littlechild, Transmission Regulation, Merchant Investment, and the Experience of SNI and Murraylink in the Australian National Electricity Market, Harvard Electricity Policy Group, Harvard Univ., Cambridge, MA, June 2003.

[6] R. P. O'Neill, B. F. Hobbs, Jr., W. R. Stewart, and M. H. Rothkopf, "The Joint Energy and Transmission Rights Auction: A General Framework for RTO Market Designs," FERC Discussion Paper, 2001.

[7] R. P. O'Neill, U. Helman, B. F. Hobbs, Jr., W. R. Stewart, and M. H. Rothkopf, "A joint energy and transmission rights auction: Proposal and properties," IEEE Trans. Power Syst., vol. 17, no. 4, pp. 1058-1067, Nov. 2002.

[8] R. O'Neill, U. Helman, R. Baldick, W. Stewart, and M. Rothkopf, "Contingent transmission rights in the standard market design," IEEE Trans. Power Syst., vol. 18, no. 4, pp. 1331-1337, Nov. 2003. 
[9] H. Salas and R. Baldick, "Pricing the Emergency Capacity in a Transmission Line", Mar. 2004.

[10] R. Baldick and E. Kahn, "Contract paths, phase-shifters, and efficient electricity trade," IEEE Trans. Power Syst., vol. 12, no. 2, pp. 749-755, May 1997.

[11] S. Harvey, W. Hogan, and S. Pope, "Transmission Capacity Reservations and Transmission Congestions Contracts", Manuscript, John F. Kennedy School of Government, Harvard Univ., Cambridge, MA, Mar. 1997.

[12] H.-P. Chao and S. Peck, "A market mechanism for electric power transmission," J. Regulatory Econ., vol. 10, no. 1, pp. 25-59, July 1996.

[13] H.-P. Chao, S. Peck, S. Oren, and R. Wilson, "Flow-based transmission rights and congestion management," Electricity J., vol. 13, no. 8, pp. $38-58,2000$

[14] W. W. Hogan, "Regional Transmission Organizations: Millenium Order on Designing Market Institutions for Electric Network Systems," Tech. Rep., Center for Business and Government, John F. Kennedy School of Government, Harvard Univ., Cambridge, MA, May 2000.

[15] W. Hogan, "Financial Transmission Right Formulations", John F. Kennedy School of Government, Harvard Univ., Cambridge, MA, Mar. 2002.

[16] L. E. Ruff, "Flowgates, contingency-constrained dispatch, and transmission rights," Electricity J., vol. 14, no. 1, pp. 34-55, Jan./Feb. 2001.

[17] R. P. O'Neill, P. M. Sotkiewicz, B. F. Hobbs, M. H. Rothkopf, and W. R. Stewart, Jr., "Efficient market-clearing prices in markets with nonconvexities," Eur. J. Oper. Res., [Online] Available ksgwww.harvard.edu/hepg., Dec. 2002, to be published.

[18] B. F. Hobbs, M. H. Rothkopf, R. P. O'Neill, and H. P. Chao, Eds., The Next Generation of Unit Commitment Models. Norwell, MA: Kluwer, International Series in Operations Research \& Management Science, 2001.

[19] W. W. Hogan, "Market-Based Transmission Investments and Competitive Electricity Markets,", Tech. Rep. 1999.

Richard P. O'Neill received the Ph.D. degree in operations research from the University of Maryland, College Park.

He is Chief Economic Advisor in the Federal Energy Regulatory Commission Office of Markets, Tariffs, and Rates, Washington, DC. He previously was on the faculty of the Department of Computer Science, Louisiana State University, Baton Rouge.

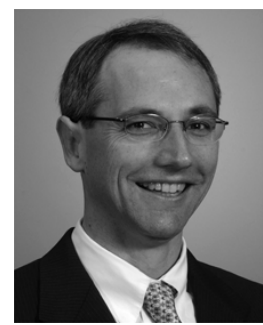

Ross Baldick (M'91) received the B.Sc. degree in mathematics and physics and the B.E. degree in electrical engineering from the University of Sydney, Australia, and the M.S. and Ph.D. degreess in electrical engineering and computer sciences in 1988 and 1990, respectively, from the University of California, Berkeley.

From 1991 to 1992, he was a Post-doctoral Fellow at the Lawrence Berkeley Laboratory. In 1992 and 1993, he was an Assistant Professor at Worcester Polytechnic Institute, Worcester, MA. He is currently a Professor in the Department of Electrical and Computer Engineering at The University of Texas at Austin.

Udi Helman received B.A. and M.A. degrees from the University of Toronto, Toronto, ON, Canada, and the Ph.D. degree in energy economics from The Johns Hopkins University, Baltimore, MD.

$\mathrm{He}$ is an Economist in the Federal Energy Regulatory Commission Office of Markets, Tariffs, and Rates, Washington, DC.

Michael H. Rothkopf received the B.S. degree in mathematics from Pomona College, Claremont, CA, and the M.S. in industrial management and Ph.D. in operations research from the Massachusetts Institute of Technology, Cambridge.

He has worked for Shell, Xerox Palo Alto Research Center, Lawrence Berkeley Laboratory, and, since 1988, as a Professor in the Business School and the Operations Research Center (RUTCOR) at Rutgers University, Piscataway, NJ. Since 1997, he has been a consultant to the Federal Energy Regulatory Commission.

William Stewart, Jr. received the B.S. degree in mechanical engineering from Tufts University, Medford, MA, the M.S. degree in management science from The Johns Hopkins University, Baltimore, MD, and the Ph.D. degree in operations research from the University of Maryland, College Park.

He is the David L. Peebles Professor of Business Administration in the Graduate School of Business at the College of William and Mary, Williamsburg, VA. 